eISSN 2444-7986

DOI: http://dx.doi.org/10.14201/orl201672.14001

\author{
Caso clínico
}

\title{
TRAUMATISMO LARINGOTRAQUEAL. DESCRIPCIÓN DE UN CASO
}

\section{Laryngotracheal trauma. A case report}

\author{
María PONCELA-BLANCO; Laura DÍEZ-GONZÁLEZ; Fernando MARTíN-PEÑA; Rosa \\ RODRIGUEZ-CRESPO; Jose María ESCAPA-GARRACHÓN
}

SACYL. Hospital General Río Carrión. Servicio de Otorrinolaringología y Patología Cervicofacial. Palencia. España

Correspondencia: lauradiezg@hotmail.com

Fecha de recepción: 3 de marzo de 2016

Fecha de aceptación: 1 de abril de 2016

Fecha de Publicación: 18 de abril de 2016

Conflicto de intereses: Los autores declaran no tener conflictos de intereses

Imágenes: Los autores declaran haber obtenido las imágenes con el permiso de los pacientes

Política de derechos y autoarchivo: se permite el autoarchivo de la versión post-print (SHERPA/RoMEO)

Licencia CC BY-NC-ND. Licencia Creative Commons Atribución-NoComercial-SinDerivar 4.0 Internacional

(๖) Universidad de Salamanca. Su comercialización está sujeta al permiso del editor

RESUMEN

\begin{abstract}
Introducción y objetivo: los traumatismos laringotraqueales son lesiones infrecuentes con importante impacto en la morbimortalidad. El manejo precoz de esta patología incrementa la supervivencia del paciente y minimiza las posibles secuelas aerodigestivas. Se estudia la evolución del caso que presentamos durante y después de su estancia hospitalaria. Descripción del caso: presentamos el caso de un paciente con traumatismo laringotraqueal contuso que precisó traqueotomía para asegurar la vía aérea y posterior reconstrucción quirúrgica con colocación de estent endolaríngeo, a fin de conservar su permeabilidad. Discusión: el diagnóstico de sospecha en los traumatismos cervicales se realiza a través de la historia clínica y del examen físico, aunque la ausencia de estos signos y síntomas no descarta la presencia de una lesión importante. La tomografía computadorizada (TC) constituye hoy en día el método de elección para el diagnóstico de traumatismos cervicales. Conclusiones: el objetivo principal en los traumatismos laringotraqueales es asegurar la vía aérea. La morbilidad y mortalidad de estas lesiones está en relación con la precocidad en la actuación. Una reparación quirúrgica temprana disminuye el índice de complicaciones tardías, mejorando la calidad de vida del paciente. El caso propuesto pretende poner de manifiesto la posibilidad de diseñar un estent laríngeo como alternativa a los estent comercializados, a fin de actuar como tutor laríngeo que evite la cicatrización estenótica y sus posibles secuelas.
\end{abstract}

PALABRAS CLAVE traumatismos del cuello; heridas penetrantes; laringe;

SUMMARY Introduction and objective: Laryngotracheal deep traumas are uncommon damages that can result in potential fatal injury. Prompt intervention significantly improves patient survival and prevents short and long-term aerodigestive tract sequelae. The progression of a patient was studied during and after his hospital stay. Case description: We report a clinical patient with a cervical trauma who required tracheotomy to secure the airway and subsequent surgical reconstruction with insertion of an endolaryngeal estent in order to preserve its permeability. 
Discussion: The diagnosis of cervical trauma is based on clinical history and physical examination. In spite of this, the absence of signs and symptoms do not reject the presence of a major injury. angioCT is now the method of choice for the diagnosis of cervical trauma. The management of this pathology depends on the severity of the injuries. Conclusions: The main objective in laryngotracheal injuries is to secure the airway. Morbidity and mortality of these lesions are related to prematurity in acting. Hence, early diagnosis is required. Prompt surgical repair decreases the rate of late complications, improving the patient's quality of life.

KEYWORDS

neck injuries; wounds, penetrating; larynx

\section{INTRODUCCIÓN}

La incidencia de los traumatismos laringotraqueales es baja -1 por 30.000 casos de los traumatismos atendidos en urgencias [1]siendo los traumatismos cerrados por accidentes de tráfico la causa más frecuente en nuestro medio [2]. En un tercio de los casos el daño se produce en la laringe y el resto en la tráquea cervical con mayor prevalencia en la zona de transición entre cricoides y primer anillo traqueal por la debilidad del tejido conectivo en esta área. A pesar de su baja incidencia tiene una mortalidad global del $2-10 \%$ [3]. El manejo precoz de estos traumatismos incrementa la supervivencia y minimiza las posibles secuelas aerodigestivas del paciente.

\section{DESCRIPCIÓN}

Varón de 49 años con traumatismo cervical tras haber sufrido un síncope con caída por las escaleras con el cuello extendido sin ningún reflejo postural defensivo de flexión cervical. Se realizó tomografía axial computadorizada (TC) cerebral y cervicotorácica, informándose de una línea de fractura vertical de la rama izquierda del hueso hioides $y$, al menos, dos líneas de fractura del cartílago tiroideo (Figura 1).

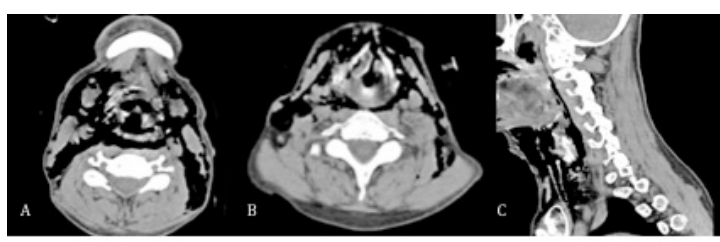

Figura 1. TC cervicotorácica. A) TC axial con fractura vertical de la rama izquierda del hueso hioides. B) TC axial con fractura anterior y posterior del cartílago tiroideo. C) TC sagital con enfisema cervicotorácico.

Se visualizaron soluciones de continuidad en ambos senos piriformes, identificándose abundante gas que disecaba los planos mus- culares cervicales, se extendía a ambos lados del cuello, cervical posterior, espacios submandibulares y región mediastínica.

Clínicamente el paciente presentaba una disnea severa progresiva, por lo que se evitó realizar una laringoscopia o fibroscopia flexible. Dada la situación clínica del paciente, así como la presencia de un importante enfisema cervical, se realizó una traqueotomía bajo anestesia local en posición semisentada y posteriormente se revisaron las lesiones. La exploración física en quirófano reveló fractura de cartílago tiroides y cricoides con desplazamiento de fragmentos y protrusión anterior del cricoides así como enfisema cervicotorácico (Figura 2). Asegurada la vía aérea, se realizó la reconstrucción de la fractura y laringoscopia. Se colocó un estent endolaríngeo diseñado con un dedo de guante con gasa en su interior.

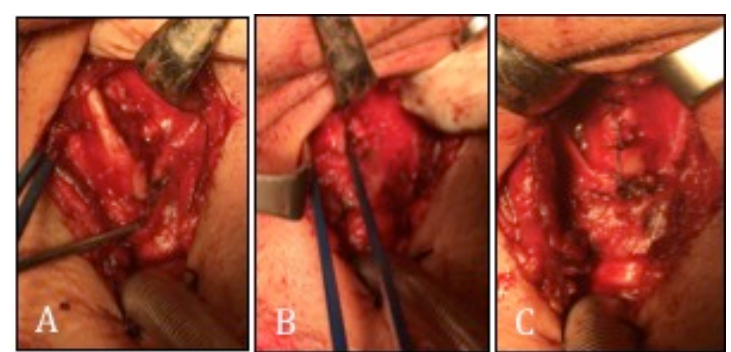

Figura 2. Fractura de cartílago A) tiroides y B) cricoides, con posterior C) reconstrucción.

Tras la intervención, el paciente fue ingresado en la unidad de cuidados intensivos con ventilación mecánica y relajación muscular los primeros seis días. Se pautó tratamiento antibiótico con amoxicilina y ácido clavulánico sustituido por ceftriaxona al presentar el paciente neumonía por Moraxella catarrahalis. Posteriormente desarrolló derrame pleural derecho y se colocó un tubo de drenaje torácico. 
Durante el seguimiento se realizaron controles periódicos con fibroscopia flexible para valorar la posición del estent y la evolución del edema laríngeo. El estent fue retirado a los 14 días tras la intervención. La TC cervicotorácica de control mostró persistencia de la fractura con mínimo desplazamiento y cabalgamiento de fragmentos sobre el margen posteroinferior del cartílago tiroides derecho (Figura 3). El paciente fue decanulado tres días después de la extracción del estent tras comprobar la permeabilidad de la luz laríngea y la movilidad glótica.

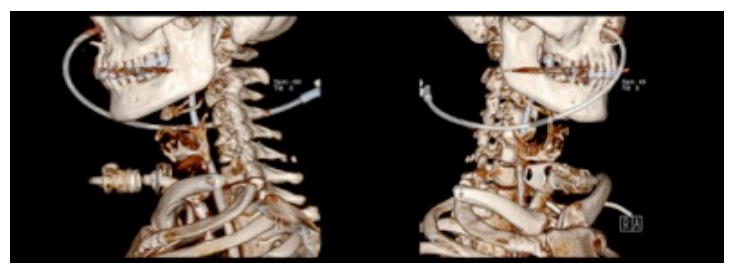

Figura 3: Reconstrucción 3D de TC cervicotorácica de control.

La evolución fue favorable, con buena mecánica respiratoria y deglutoria, siendo dado de alta al cuarto día posterior a la decanulación. Las revisiones posteriores fueron realizadas en su centro de referencia el cual informó de la resolución de la patología laríngea.

\section{DISCUSIÓN}

Los traumatismos laringotraqueales son lesiones infrecuentes con un importante impacto en la morbimortalidad [1]. La mayoría de traumatismos cervicales tienen lugar en la zona II desde el cartílago cricoides al ángulo de la mandíbula, presentando en esta zona el mayor índice de lesiones en el tracto aerodigestivo. Sin embargo la mortalidad es superior si el área afectada corresponde a la zona I comprendida entre clavícula y horquilla esternal, debido al riesgo de lesiones vasculares importantes y lesiones intratorácicas asociadas (Tabla 1) [4].

El caso que hemos presentado corresponde al de un varón de 49 años con traumatismo laríngeo cerrado tras sufrir un síncope. El paciente presentó fractura del hueso hioides, cartílago tiroides y cricoides, asociado a enfisema cervicotorácico.

El diagnóstico de sospecha se realiza a través de la historia clínica y del examen físico siendo frecuente el enfisema subcutáneo, contusiones y laceraciones que evidencian la afectación de estructuras vasculares y traqueales. Los síntomas de presentación más habituales son disnea, disfonía, disfagia y odinofagia [1]. Sin embargo la ausencia de estos signos y síntomas no descarta la presencia de una lesión importante. En la serie de 89 pacientes presentada por Randall, et al. [5], los signos y síntomas más frecuentes fueron dificultad respiratoria (27\%), enfisema subcutáneo $(21 \%)$, estridor $(17 \%)$ y disfagia (14\%). El $14,2 \%$ de los pacientes no presentaron síntomas ni signos que indicasen una lesión laringotraqueal subyacente, evidenciando la falta de correlación con el grado de afectación existente. El cartílago tiroides fue la estructura laringotraqueal más frecuentemente lesionada y los tejidos blandos afectados con mayor incidencia se localizaron en la región supraglótica. En el caso que mostramos, el enfisema y la disnea fueron los síntomas y signos de presentación. La exploración mostró varias líneas de fractura en el cartílago tiroides y cricoides asociadas a fractura del hueso hioides.

Tabla 1. Zonas anatómicas del cuello.

\begin{tabular}{ll}
\hline Zona I & Se extiende desde las clavículas hasta el \\
& borde inferior del cartílago cricoides. Las \\
& estructuras de mayor riesgo en esta zona \\
& son los grandes vasos (venas subclavias, \\
& venas braquiocefálicas, carótida común, \\
& cayado aórtico y venas yugulares), trá- \\
& quea, la glándula tiroides, el esófago, el \\
& conducto torácico, el plexo braquial, el \\
& nervio vago y los ápices pulmonares. \\
\hline Zona II & Se extiende desde el cartílago cricoides \\
& hasta el ángulo de la mandíbula. Las \\
& estructuras más importantes en esta re- \\
& gión incluyen las carótidas, las arterias \\
& vertebrales, las venas yugulares, faringe, \\
& laringe, tráquea, esófago, columna cervical \\
& y medula espinal. \\
\hline Se extiende desde la parte superior del \\
ángulo de la mandibula hasta la base del \\
cráneo, pudiendo afectarse las carótidas \\
externas, las carótidas internas extracra- \\
neales, las arterias vertebrales, las venas \\
yugulares, la medula espinal, los nervios \\
VII, IX, X, XI y XIl y la hipofaringe.
\end{tabular}

En los pacientes estables hemodinámica y respiratoriamente, la exploración debe completarse con una nasofibrolaringoscopia a fin de valorar la permeabilidad faringolaríngea. La TC es el técnica de imagen de primera línea en los traumatismos cervicales, complementando a la exploración clínica, pues es 
una técnica rápida y no invasiva que permite evaluar el tracto laringotraqueal [6]. La angiografía por tomografía computadorizada (angioTC) debe realizarse ante la sospecha de lesiones vasculares, presentando una elevada sensibilidad y especificidad en el diagnóstico de este tipo de lesiones - del 100\% y $98,6 \%$ respectivamente [2] - y ofrece una valoración global del área cervical, reduciendo el número de exploraciones quirúrgicas y aportando información sobre la necesidad de estudios adicionales con esofagoscopia o angiografía [7].

La prioridad en el manejo de los traumatismos laringotraqueales es mantener la vía aérea permeable. La intubación orotraqueal puede provocar lesiones iatrogénicas que agravan la lesión existente y empeoran el edema local por lo que su realización está limitada a situaciones concretas con mucosa laríngea indemne y sin desplazamiento del esqueleto laríngeo. En caso contrario es preferible la realización de traqueotomía bajo anestesia local $[8,9]$. El retraso en la reparación quirúrgica incrementa la posibilidad de estenosis en la vía aérea, existiendo mayor incidencia de complicaciones en las actuaciones posteriores a las 24 horas de la lesión [10, 11]. En el caso presentado, la intubación orotraqueal no fue posible y se practicó traqueotomía bajo anestesia local con posterior reconstrucción de la fractura y colocación de estent endolaríngeo. El paciente evolucionó favorablemente, siendo posible la decanulación, sin repercusión posterior en la respiración, fonación o deglución.

Tabla 2. Clasificación de lesiones laríngeas de SchaeferFurhrman.

\begin{tabular}{ll}
\hline Grupo 1 & $\begin{array}{l}\text { Hematoma endolaríngeo menor. Fractura } \\
\text { no detectable. }\end{array}$ \\
Grupo 2 & $\begin{array}{l}\text { Edema, hematoma, mínima disrupción, } \\
\text { mucosa sin exposición de cartílago. }\end{array}$ \\
Grupo 3 & $\begin{array}{l}\text { Fracturas no desplazadas. } \\
\text { Edema endolaríngeo masivo, inmovilidad } \\
\text { de cuerda vocal, fracturas desplazadas } \\
\text { con cartílago expuesto, compromiso de la } \\
\text { vía aérea. } \\
\text { Igual al grupo } 3 \text { con dos o más líneas de } \\
\text { fractura o traumatismo masivo sobre la } \\
\text { mucosa laríngea. } \\
\text { Disrupción cricotraqueal. }\end{array}$ \\
Grupo 5
\end{tabular}

El manejo de los traumatismos cervicales depende de la gravedad de las lesiones. Siguiendo la escala propuesta por Schaefer-
Fuhrman (Tabla 2). Se distinguen 5 grupos que comprenden desde mínimo compromiso de la vía aérea sin laceración de la mucosa (grupo I), hasta separación laringotraqueal (grupo V). La mayoría de los autores preconizan tratamiento quirúrgico ante la rotura de la mucosa y la fractura del esqueleto laringotraqueal, reservando el tratamiento conservador -mediante antibióticos, corticoides y vigilancia estrecha- en lesiones menores y sin dificultad respiratoria $[8,12]$.

\section{CONCLUSIONES}

Las lesiones penetrantes laringotraqueales son infrecuentes. El objetivo principal es asegurar la vía aérea. La morbilidad y mortalidad de estas lesiones está en relación con la precocidad en la actuación, para ello es necesario un diagnóstico temprano, basado en la historia clínica y la exploración física. Como técnica de imagen se recomienda la TC a fin de descartar patologías que pudieran pasar desapercibidas en un primer momento. La reparación quirúrgica precoz disminuye el índice de complicaciones tardías mejorando la calidad de vida del paciente. Consideramos necesario asegurar una cicatrización no estenótica de la laringe con la colocación de un estent siempre que existan dudas de su permeabilidad.

\section{BIBLIOGRAFÍA}

1. Schaefer SD. The treatment of acute external laryngeal injuries. 'State of the art'. Arch Otolaryngol Head Neck Surg. 1991;117:35-9.

2. Garcia-Zornoza R, Morales-Angulo C, Gonzalez-Aguado R, Acle-Cervera L, Cortizo-Vazquez E, Obeso-Aguera S. Neck injuries. Acta Otorrinolaringol Esp. 2012;63:47-54.

3. Bell RB, Osborn T, Dierks EJ, Potter $\mathrm{BE}$, Long WB. Management of penetrating neck injuries: a new paradigm for civilian trauma. J Oral Maxillofac Surg. 2007;65:691-705.

4. Jurkovich GJ, Zingarelli W, Wallace J, Curreri PW. Penetrating neck trauma: diagnostic studies in the asymptomatic patient. J Trauma. 1985;25:819-22. 
5. Randall DR, Rudmik LR, Ball CG, Bosch JD. External laryngotracheal trauma. Laryngoscope. 2014;124:E123E133.

6. Stanley RB, Jr. Value of computed tomography in management of acute laryngeal injury. J Trauma. 1984;24:359-62.

7. Steenburg SD, Sliker CW, Shanmuganathan K, Siegel EL. Imaging evaluation of penetrating neck injuries. Radiographics. 2010;30:869-86.

8. Schaefer SD. The acute management of external laryngeal trauma. A 27-year experience. Arch Otolaryngol Head Neck Surg. 1992;118:598-604.
9. O'Mara W, Hebert AF. External laryngeal trauma. J La State Med Soc. 2000;152:218-22.

10. Reece GP, Shatney $\mathrm{CH}$. Blunt injuries of the cervical trachea: review of 51 patients. South Med J. 1988;81:1542-8.

11. Butler AP, Wood BP, O'Rourke AK, Porubsky ES. Acute external laryngeal trauma: experience with 112 patients. Ann Otol Rhinol Laryngol. 2005;114:361-8.

12. Fuhrman GM, Stieg FH, 3rd, Buerk CA. Blunt laryngeal trauma: classification and management protocol. J Trauma. 1990;30:87-92. 